Ann. Biol. anim. Bioch. Biophys., 1979, 19 (3 B), 955-958.

\title{
Influence de la vitesse d'évacuation gastrique des protéines et des lipides sur l'utilisation digestive chez le veau préruminant
}

\author{
P. GUilloteAU, R. TOULLEC, P. PATUREAU-MIRAND * \\ avec la collaboration technique de S. BOUSSION, J. LAREYNIE, Monique LESNE, Y. MANIS \\ Station de Recherches Zootechniques, I.N.R.A., \\ 65, rue de Si-Brieuc, 35042 Rennes Cedex \\ * Laboratoire d'Etudes du Méfabolisme Azoté, I.N.R.A. \\ Theix, Saint-Genès-Chompanelle, 63110 Beaumont.
}

Summary. Effect of the gastric emptying rate of protein and lipid on their digestive utilization in the preruminant calf.

The replacement of skim milk by other protein sources in milk substitutes increased the rate of fat and protein abomasal emptying. The aim of this trial was to study the effect of this acceleration on digestibility. Seven preruminant calves were fitted with a catheter in the duodenum immediately after the pylorus. Two diets were used containing either skim milk (control diet) as the only source of protein or hydrolysed fish (fish diet) as the main protein source. These milk substitutes were either ingested by the calves or infused slowly or quickly into the duodenum in order to simulate the respective protein gastric emptying rates of the control and the fish diets (fig. 1, table 1). The apparent digestibility of nitrogen, and particularly of lipid, decreased when each diet was infused at its nitrogen gastric emptying rate (table 2). Infusion at a higher speed (control diet) increased this effect, while infusion at a slower rate (fish diet) suppressed it. The time spent in the abomasum and the rate of arrival in the duodenum largely influenced protein and fat digestibility. This would at least partly explain the lower digestibility of the milk substitutes containing replacement proteins.

Chez le veau préruminant, le remplacement de la poudre de lait écrémé des aliments d'allaitement par d'autres sources de protéines, entraîne une accélération de l'évacuation gastrique des lipides et des matières azolées, due principalement à la suppression de la coagulation (Toullec, Thivend ef Mathieu, 1971). Cette accélération peut influencer défavorablement la digestibilité des lipides et des protéines, du fait de leur temps de contact plus court avec les sécrétions digestives agissant dans la caillette et de leur arrivée massive dans le duodénum. Le but de cet essai était d'étudier les effets respectifs de ces deux facteurs.

Sept veaux mâles de race Frisonne ont été munis d'un cathéter introduit dans le duodénum proximal. Ils ont reçu deux laits de remplacement dont les protéines provenajent en quasi-totalité du lait écrémé (aliment Témoin) ou en majeure partie d'un concentrat de poisson partiellement hydrolysé (aliment Poisson). La quantité de 
matière sèche distribuée par jour était de $57 \mathrm{~g} / \mathrm{kg}$ de poids vif 0,75 . Les animaux étaient âgés d'au moins un mois au moment des mesures.

Les laits ont été soit ingérés par les veaux, soit infusés lentement ou rapidement dans leur duodénum (fig. 1). L'infusion a été effectuée à l'aide d'une pompe péristaltique permettant de simuler les vitesses d'évacuation gastrique observées précédemment (Guilloteau et al., 1975) pour les matières azotées de deux aliments très voisins de ceux utilisés dans cet essai. Pendant l'infusion, la moitié de l'eau de la ration était proposée au seau, afin de maintenir les mécanismes réflexes liés à l'ingestion ; le reste était utilisé pour diluer l'aliment. Pendant chaque période de mesures (2/veau/traitement), les quantités proposées, refusées et excrétées ont été pesées et échantillonnées pendant cinq jours consécutifs.

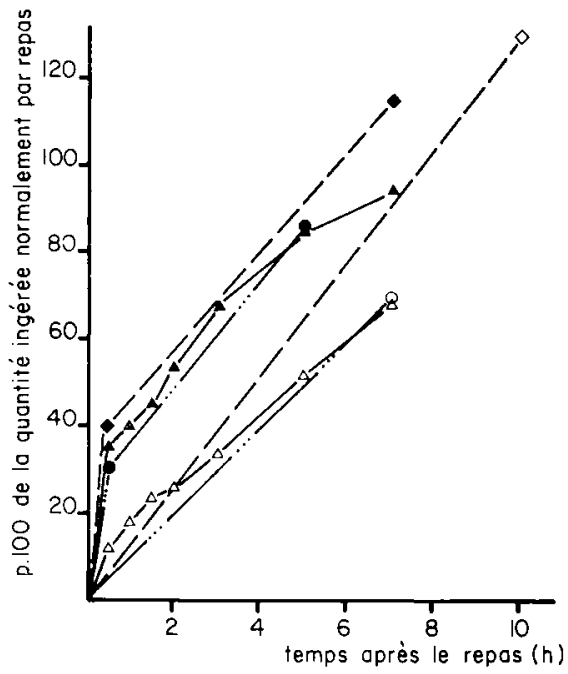

FIG. 1. - Simulation de l'évacuation gastrique des matières azotées par infusion lente ou rapide.

$\triangle$ Evacuation gastrique des matières azotées de l'aliment témoin ; évacuation gastrique des matières azotées de l'aliment Poisson ; $-\cdots-0$ infusion lente (repas du matin) 口- - - infusion lente (repas du soir) ; $-\cdots-\bullet$ infusion rapide (repas du matin) ; - - infusion rapide (repas du soir).

Lors de la simulation des évacuations gastriques, les quantités réellement infusées sont voisines de celles qui sont programmées (tabl. 1). La digestibilité apparente de chaque aliment diminue lorsqu'il est infusé dans le duodénum à la vitesse d'évacuation gastrique de ses matières azotées (tabl. 2). L'infusion à une vitesse supérieure (aliment Témoin) accroît cet effet ; l'infusion à une vitesse inférieure (aliment Poisson) l'annule. La suppression du passage dans la caillette (et/ou dans la bouche) et donc probablement le raccourcissement du temps de contact avec les sécrétions agissant dans cet organe, ainsi que l'augmentation de la vitesse d'arrivée dans le duodénum, ont un effet défavorable sur la digestibilité. Cet effet est plus marqué pour les lipides, ce qui souligne l'importance de l'hydrolyse des triglycérides dans la caillette (Toullec et Felinski, 1971), sous l'influence de l'estérase prégastrique (Toothill, Thompson et Edwards-Webb, 
1976), sans toutefois exclure une action néfaste de l'arrivée dans le duodénum de quantités importantes de protéïnes moins attaquées dans la caillette. Il serait cependant souhaitable de vérifier que les phénomènes digestifs intervenant dans l'intestin grêle (transit, sécrétions digestives, etc...) ne sont pas trop modifiés par l'infusion.

\section{TABLEAU 1}

Infusion du lait de remplacement : quantités programmées et quantités infusées (moyennes ef écarts-types des échantillons)

\begin{tabular}{|c|c|c|c|c|c|}
\hline \multirow{2}{*}{\multicolumn{2}{|c|}{$\begin{array}{l}\text { Aliment } \\
\text { Infusion }\end{array}$}} & \multicolumn{2}{|c|}{ Témoin } & \multicolumn{2}{|c|}{ Poisson } \\
\hline & & lente & rapide & lente & rapide \\
\hline Quantités infusées par jour : mesurées/programmées. & $\mathrm{R}$ & $\begin{array}{c}0,95 \\
(0,06)\end{array}$ & $\begin{array}{c}0,90 \\
(0,03)\end{array}$ & $\begin{array}{c}1,00 \\
(0,02)\end{array}$ & $\begin{array}{c}0,98 \\
(0,01)\end{array}$ \\
\hline \multirow{2}{*}{$\begin{array}{l}\text { Quantités infusées pendant le repas du matin/quantités } \\
\text { infusées par jour }\end{array}$} & $\mathrm{R}$ & $\begin{array}{c}0,45 \\
(0,02)\end{array}$ & $\begin{array}{c}0,47 \\
(0,02)\end{array}$ & $\begin{array}{l}0,47 \\
(0,01)\end{array}$ & $\begin{array}{c}0,48 \\
(0,01)\end{array}$ \\
\hline & $P$ & $\begin{array}{c}0,46 \\
(0,00)\end{array}$ & $\begin{array}{c}0,48 \\
(0,00)\end{array}$ & $\begin{array}{l}0,47 \\
(0,01)\end{array}$ & $\begin{array}{c}0,47 \\
(0,01)\end{array}$ \\
\hline \multirow{2}{*}{$\begin{array}{l}\text { Quantités infusées pendant la première demi-heure/ } \\
\text { quantiłés infusées lors de chaque repas }\end{array}$} & $\mathbf{R}$ & - & $\begin{array}{c}0,38 \\
(0,03)\end{array}$ & $\overline{-}$ & $\begin{array}{c}0,36 \\
(0,04)\end{array}$ \\
\hline & $P$ & $\overline{-}$ & $\underline{0,35}$ & $\overline{-}$ & $\underline{0,35}$ \\
\hline
\end{tabular}

$R$ : Valeur réelle; $P$ : Valeur programmée.

\section{TABLEAU 2}

Influence de l'infusion de l'aliment dans le duodénum sur la digestibilité de l'azołe et des lipides (moyennes et écarts-types des échantillons)

\begin{tabular}{|c|c|c|c|c|c|c|}
\hline \multirow[b]{2}{*}{ Traitement } & \multicolumn{3}{|c|}{ Aliment Témoin $\left({ }^{(1,2}\right)$} & \multicolumn{3}{|c|}{ Aliment Poisson $(\mathbf{1 , 2})$} \\
\hline & Ingestion & $\begin{array}{c}\text { Infusion } \\
\text { lente }\end{array}$ & $\begin{array}{l}\text { Infusion } \\
\text { rapide }\end{array}$ & Ingestion & $\begin{array}{l}\text { Infusion } \\
\text { lente }\end{array}$ & $\begin{array}{l}\text { Infusion } \\
\text { rapide }\end{array}$ \\
\hline $\begin{array}{l}\text { Digestibilité apparente } \\
\left(\text { p. 100) }\left({ }^{3}\right):\right.\end{array}$ & & & & & & \\
\hline - Azote $\ldots \ldots \ldots \ldots \ldots$ & $\begin{array}{l}96,3\left(^{a}\right) \\
(1,1) \\
92,9\left(^{(a)}\right. \\
(4,0)\end{array}$ & $\begin{array}{l}94,8(b) \\
(1,8) \\
86,5(b e) \\
(8,7)\end{array}$ & $\begin{array}{l}92,6(c g) \\
(2,9) \\
80,0(c) \\
(5,2)\end{array}$ & $\begin{array}{l}92,8(c a h) \\
(2,7) \\
92,8(a b) \\
(5,3)\end{array}$ & $\begin{array}{l}95,0\left({ }^{b c e}\right) \\
(0,9) \\
96,2(a) \\
(2,3)\end{array}$ & $\begin{array}{l}89,0(f g h) \\
(5,5) \\
82,4(c d e) \\
(10,4)\end{array}$ \\
\hline
\end{tabular}

(1) Les protéines de l'aliment Témoin provenaient presque exclusivement de la poudre de lait écrémé ; celles de l'aliment Poisson étaient apportées pour 74 p. 100 par un concentrat protéique de poissons blancs partiellement hydrolysés, le reste étant fourni par de la poudre de lactosérum el des acides aminés de synthèse.

(2) Les matières grasses étaient du suif qui avait été incorporé dans du lait écrémé (aliment Témoin) ou du lactosérum (aliment Poisson) concentrés ; les 2 mélanges liquides ainsi obtenus avaient été homogénéisés et séchés selon le procédé Spray.

$\left.{ }^{3}\right)$ Les valeurs de la même ligne accompagnées d'une même lettre ne sont pas significativement différentes $(P<0,05)$. 
En conclusion, le temps de séjour dans la caillette et la vitesse d'arrivée dans le duodénum ont une influence importante sur la digestibilité des protéines et surtout sur celle des lipides. La vitesse d'évacuation gastrique a probablement davantage d'incidence chez le très jeune veau, compte-tenu du niveau plus faible des sécrétions enzymatiques pancréatiques (Ternouth ef Roy, 1973). Cela explique au moins en partie l'utilisation digestive moins élevée des aliments contenant des protéines de substitution.

Commission CNERNA Digestion-Absorption/Association des Physiologistes, Paris 5-6 octobre 1978.

\section{Références}

GUILLOTEAU P., PARUELLE J.-L., TOULLEC R., MATHIEU C.-M., 1975. Utilisation des protéines par le veau préruminant à l'engrais. III. Influence du remplacement des protéines du lait par celles du poisson sur la vidange stomacale. Ann. Zootech., 24, 243-253.

TERNOUTH J. H., ROY J. H. B., 1973. The effect of diet and feeding technique on digestive function in the calf. Ann. Rech. vét., 4, 13-18.

TOOTHILL J., THOMPSON S. Y., EDWARDS-WEBB J. D., 1976. Studies on lipid digestion in the preruminant calf. The source of lipolytic activity in the abomasum. Br. J. Nutr., 36, 439-447.

TOULLEC R., FELINSKI L., 1971. Hydrolyse des triglycérides à chaînes longues dans la caillette du veau préruminant. Ann. Biol. anim. Bioch. Biophys., 11, 315-317.

TOULLEC R., THIVEND P., MATHIEU C.-M., $1971 . \quad$ Utilisation des protéines du lactosérum par le veau préruminant. I. Vidange stomacale comparée du lait entier et de deux laits de remplacement ne contenant que des protéines de lactosérum comme sources de matières azotées. Ann. Biol. anim. Bioch. Biophys., 11, 435-453. 